Bol. Acad. peru. leng. 64. 2018 (221-234)

\title{
DE TROL A TROLEAR: NEOLOGISMOS COLOQUIALES EN EL HABLA CASTELLANA
}

\author{
Carola Tueros \\ Universidad de Piura
}

Fecha de recepción:

$01 / 08 / 2018$

Fecha de aceptación:

$31 / 10 / 2018$

Cuando hablamos de neologismo nos referimos a un término, acepción, expresión o giro nuevo en una lengua; ciertamente, el vocablo viene del griego

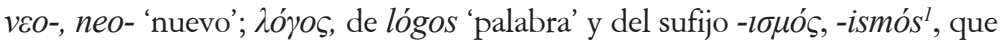
en español forma sustantivos que significan tendencia o cualidad.

Si precisamos la definición de coloquialismo, el Diccionario de la lengua española (DLE) nos dice que es una palabra o expresión coloquial o la tendencia a usar coloquialismos ${ }^{2}$. Pero ¿qué es lo coloquial? En su

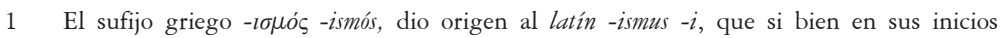
acompañaba a verbos (christiānismus, cristianizó; exorcismus, exorcizó), también tenía como base radicales nominales (pāgānismus, paganismo; dēnārismus, cierto impuesto). Este patrón establecido por el latín siguió y, por eso, tenemos varios sustantivos con dicho sufijo: anexionismo, simbolismo, feminismo, cretinismo, leísmo, etcétera.

2 Según el Diccionario de la lengua española (2014) es la palabra o expresión coloquial. La tendencia a usar coloquialismos. De acuerdo con el Diccionario clave (2012) es la palabra o expresión usadas corrientemente. 
primera acepción, el $D L E$ dice que es lo relativo al coloquio, esto es, a la conversación entre dos o más personas; no obstante, en su significado específico y más relacionado con el tema que abordamos es lo empleado corrientemente, lo propio de una conversación informal o distendida o, si se entiende mejor, relajada.

En palabras del filólogo Antonio Briz, «el español coloquial es un registro, nivel de habla, un uso determinado por la situación, por las circunstancias de la comunicación. No es dominio de una clase social, sino que caracteriza las realizaciones de todos los hablantes de una lengua. Es cierto que es el único registro que dominan los hablantes de nivel sociocultural bajo, medio-bajo, pero en absoluto les es exclusivo» (2010: 29). En este último punto estamos de acuerdo: es fácil comprobar que los hablantes de distintos niveles socioeconómicos y culturales y de distintas competencias lingüísticas empleamos coloquialismos, lo cual obviamente depende del contexto. Así, por ejemplo, se encuentran el profesor que quiere tener un lenguaje más llano con los alumnos y les recomienda «chancar para no jalar», en vez de «estudiar para no desaprobar»; el alumno universitario que le dice "chancón» al amigo estudioso; el médico que saluda a su paciente con un «qué tal», en lugar de «buenos días»; el profesional que le dice a su colega que tiene «harta chamba» por «mucho trabajo»; la niñera que le dice «cucufata» a la cocinera que es santurrona o muy devota; el jefe de sistemas que escribe un artículo y lo titula Evita que te «baneen», en vez de Evita que te bloqueen, etcétera.

Por lo tanto, si unimos las dos palabras neologismo y coloquial, estamos hablando de la unidad léxica nueva de uso familiar, informal, espontáneo y cotidiano que nace, justamente, porque la lengua no es inmutable. Ya lo decía Manuel Alvar Ezquerra: «Ninguna lengua puede conformarse con el vocabulario que posee en el momento de su nacimiento (...), pues de ser así quedaría obsoleta sin poder seguir las transformaciones que se producen en el mundo extralingüístico, no sería capaz de progresar y desaparecería al no llegar a satisfacer las necesidades de los usuarios» (2008: 9).

Por otra parte, Gloria Guerrero en su obra Neologismos en el español actual (2010: 10-11) no se equivoca al enunciar que el neologismo es una 
https://doi.org/10.46744/bapl.201802.012

innovación en la lengua y ya se trate de un descubrimiento científico, de un progreso industrial, de una modificación de la vida social, de un movimiento ideológico, de una nueva manera de sentir o comprender, de un enriquecimiento de la vida moral, constituye una necesidad imperiosa; pues todos creamos nuevas palabras, tanto el culto como el ignorante, el teórico como el pragmático, el empleado como el desempleado, el adulto como el joven e, incluso, hasta el infante, y las usamos sin darnos cuenta, a veces, pero siempre procurando entendernos.

Los neologismos coloquiales no son exclusivos del lenguaje oral. Cabe recordar aquí que conversar no es hablar coloquialmente, hay conversaciones que no son coloquiales; por ejemplo, en un debate, una disertación, una entrevista formal, etc., no podemos confundir el registro coloquial con la conversación. Aunque es cierto que aparecen con mayor frecuencia en la oralidad, encontramos neologismos coloquiales también en el lenguaje escrito, más aún, en la era informática en que vivimos donde todos tenemos conversaciones internáuticas o electrónicas y nos comunicamos vía chat, mensajería instantánea, correo electrónico, mailing list o lista de correos, mensaje de texto, wasap, foros de discusión, Skype, Twitter, Reddit, Instagram, Tumblr, etcétera. En otras palabras, los neologismos coloquiales están llegando y permaneciendo en la lengua por la difusión inmediata y extensa que proporcionan las distintas redes sociales. Así tenemos los verbos banear (por el inglés ban prohibición), bloguear (del inglés blogging derivado a su vez de to blog), feisbuquear (forma adaptada de la red social Facebook), guglear (por el buscador Google de la compañía del mismo nombre), tuitear (enviar tuits, mensajes a través de la red social Twitter), wasapear o guasapear (transmitir mensajes gratuitos o wasaps); los sustantivos bloguero (de blogger persona que tiene un blog), booktuber ('persona que habla de libros o que comparte sus lecturas por medio de la plataforma YouTube'), meme (de men. memorándum; imagen, video o texto burlesco del ciberespacio), tuitero (usuario de Twitter), wasap o guasap (mensaje gratuito enviado por la aplicación de mensajería instantánea WhatsApp), webinario (de web y seminario, curso impartido a distancia a través de la web), youtuber ('persona que hace videos y los transmite por YouTube'), etcétera. 
https://doi.org/10.46744/bapl.201802.012

Centrándonos en el objetivo de nuestra ponencia, analizaremos los neologismos coloquiales trol, trolear y sus derivaciones troleando o trolling, trolero, trolera, troleada, troleado, que han surgido, justamente, por el auge de la comunicación inmediata y de las redes sociales, cuya característica es la hibridez entre lo oral y lo escrito.

Estos neologismos coloquiales tienen un común denominador de formación lingüística: el término trol, que está en el diccionario académico, pero con una acepción distinta a como suele utilizarse en el discurso mediado por computadora o canales informáticos. El DLE lo registra morfológicamente como un sustantivo masculino que alude al monstruo maligno de la mitología escandinava. Atendiendo a los usos semánticos actuales de los coloquialismos en mención, podemos decir que están más vinculados a la significación del sustantivo y del verbo anglosajón troll y to troll ${ }^{3}$ que, según como lo expone el diccionario inglés Cambridge (2003) en el campo de la computación, significan o bien la persona que deja mensajes provocadores adrede o bien la acción de dejar intencionalmente un mensaje provocador en algún sitio de internet con el objetivo de generar atención o generar algún problema. Otros diccionarios como el Oxford English Dictionary registran la palabra troll ya desde $1992^{4}$.

Trol, entonces, es la persona que critica, molesta o expone su negatividad en el ciberespacio: Es un trol, siempre se burla o provoca enojo en el internauta. También se le llama trol al texto o comentario negativo publicado en internet: Publicó un trol en el blog.

Trolear es el verbo que denota acción y efecto de molestar o burlarse de alguien intencionalmente: En YouTube, hincha peruano trolea

3 Cambridge Advanced Learner's Dictionary (2003). United Kingdom: Cambridge University Press, pág. 1367. Textualmente en inglés: Troll: a well-constructed troll will provoke irate or confused responses from flamers and newbies. To troll: To leave an intentionally annoying message on a part of the Internet in order to get attention or cause trouble: His hobby is trolling for newbies

4 Con la acepción de una persona que hace una publicación en línea deliberadamente ofensiva o provocativa. 
https://doi.org/10.46744/bapl.201802.012

a reportero de FOX Sports en pleno enlace ; WhatsApp: joven «trolea» a su mamá y su respuesta se hace viral ${ }^{6}$. Se obtiene por la unión de trol-, que actúa como lexema o raíz más el sufijo -ear, el cual se remonta a -idiāre, variante popular del sufijo culto -izāare. El sufijo -ear es muy productivo y se emplea, como acota David Pharies (2002: 184), para derivar verbos factitivos y, más frecuentemente, iterativos, de la primera conjugación, sobre bases nominales (sustantivos y adjetivos). Entre los derivados internos españoles en -ear de aparición temprana, unos pocos se basan en adjetivos como blanquear (blanco), clarear (claro), malear (malo), etc. Son más numerosas las derivaciones a partir de sustantivos como señorear (señor), carrear (carro), cocear (coz), sortear (suerte), vocear (voz), etc. ${ }^{7}$

Manuel Seco (2002: 158) consolida lo mentado por Pharies al ratificar que -ear es un sufijo de verbos derivados de nombres o de adjetivos. Añade que a veces tiene significación incoativa (azulear); aunque, por lo general, significa 'tener o dar el objeto o la cualidad nombrada': agujerear, apalear, pasear. ${ }^{8}$

Trolear, por consiguiente, es un verbo con sufijo infinitivo que atañe a la palabra que lo causa; esto es, de trol la acción de 'tomar el pelo, vacilar o gastar una broma, por lo general pesada'; corresponde a la familia léxica del sustantivo trol; y su uso, con sus respectivas derivaciones, son admitidos porque nuestro sistema español o lengua castellana tiene una gran flexibilidad para la formación de palabras nuevas por derivación.

5 La República. (5 de octubre del 2017). En YouTube, hincha peruano trolea a reportero de FOX Sports en pleno enlace. Recuperado de http://larepublica.pe/deportes/1106385youtube-hincha-peruano-trolea-a-reportero-de-fox-sports-en-vivo

6 Diario Correo. (07 de mayo del 2017). WhatsApp: joven «trolea» a su mamá y su respuesta se hace viral. Recuperado de https://diariocorreo.pe/miscelanea/whatsapp-joven-trolea-asu-mama-y-su-respuesta-se-hace-viral-fotos-748234/

7 Según el modo de acción, hay verbos frecuentativos e iterativos que expresan acciones compuestas de varios actos iguales y repetidos: golpear, manosear, vagabundear, patear, besuquear donde aparece la terminación -ear indicando repetición. Y, atendiendo el significado léxico, se puede hablar de verbos factitivos, en los que el sujeto no realiza la acción, sino que la hace ejecutar: Ana se ba becho una tienda; María se empareja el pelo cada mes, etcétera.

8 Hay que anotar que incoativo/va es un adjetivo que implica o denota el principio de una cosa o de una acción progresiva.

Bol. Acad. peru. leng. 64(64), 2018 / e-ISSN: 2708-2644 
Algunos jóvenes emplean la palabra con doble l(troll, trollear) tanto por analogía de la palabra noruega troll 'ser sobrenatural' como por el sustantivo anglosajón troll, ya que ambas palabras extranjeras se escriben con doble $l$ : Mark Hamill se une a la moda de trollear a los fans de 'Star Wars'; Mariab Carey responde a críticas y la vuelven a 'trollear' por árbol de navidad ${ }^{10}$; Existe una página en Facebook llamada 1000 formas de trollear. No obstante, se recomienda usar la forma española trol con su respectivo plural troles: Por qué usted también es un 'trol' en internet (aunque aún no lo sepa) ${ }^{11}$; "Los troles pornográficos de internet me arruinaron la vida»: la dramática confesión de Victoria ${ }^{12}$.

La palabra con la acepción 'personaje mitológico maligno de bosques y grutas', ya mencionada anteriormente, se incorporó al diccionario académico en el año 1989, pero sus orígenes datan de 1610 o principios del siglo $\mathrm{XVII}^{13}$. Haciendo una analogía con estos feos duendes, se ha denominado trol y troles, en el mundo internáutico, a aquellos usuarios que hacen comentarios negativos, insultantes o agresivos porque, justamente, los asociamos con la idea de alguien aislado, oscuro, malintencionado y con carácter maligno que se regocija malogrando todo a su paso con la porra o bastón y su fuerza arrolladora, incluso a los troles cibernéticos se les suele graficar con la imagen de estas criaturas perversas pegadas a un computador y hasta artículos en la red nos mencionan sus características. Por ejemplo, sarcásticos, disruptivos, iracundos, conflictivos, etcétera; así como una tipología: trol matón (amenaza al autor del post y demás comentaristas), pirata o hacker

9 De Miguel, A. (19 de setiembre del 2017). Mark Hamill se une a la moda de trollear a los fans de 'Star Wars'. Recuperado de http://www.fotogramas.es/Noticias-cine/MarkHamill-trollea-fans-star-wars

10 Aldape, S. (3 de octubre del 2017). Mariah Carey responde a críticas y la vuelven a 'trollear' por árbol de navidad. Recuperado de https://anton.com.mx/2017/10/mariahcarey-responde-criticas-la-vuelven-trollear-arbol-navidad/

11 Pérez, R. (8 febrero del 2017). Por qué usted también es un 'trol' en internet (aunque aún no lo sepa) en El Confidencial. Recuperado de https://www.elconfidencial.com/ tecnologia/2017-02-08/trolls-internet-comentarios_1328031/

12 BBC Mundo. (24 de octubre del 2017). «Los troles pornográficos de internet me arruinaron la vida»: la dramática confesión de Victoria. Recuperado de http://www.bbc. com/mundo/noticias-41735321.

13 Proviene de la palabra nórdica antigua troll que significa gigante o demonio. El término fue adoptado más ampliamente en inglés a mediados del siglo XIX. 
https://doi.org/10.46744/bapl.201802.012

(amenaza con dañar con virus el blog), fan (defiende a muerte a sus ídolos sin preocuparse en ofender a quienes piensan distinto), vomitón (no argumenta, simplemente insulta), payaso (se mofa de todo), tiquismiquis (el que busca cualquier error por insignificante que sea), enlace (coloca enlaces o vínculos de otras páginas en tu blog), etcétera.

En el mundo infantil este duende, el trol, ha perdido la característica de maligno para convertirse en un ser amable, alegre, optimista y bondadoso, basta ver la cinta animada estadounidense del 2016 titulada Trolls $^{14}$. No obstante, hoy en día, el neologismo se sigue relacionando con la acepción del sustantivo trol (castellanizado) o troll (palabra extranjera), por su característica de ser grotesco, peleón, antisocial e hiriente que se oculta tras la pantalla de un computador para causar algún disturbio o problema en internet. Cabe anotar que el nombre de la película hecha por computadora, Trolls, presenta el plural con una -s, y no con el morfema flexivo nominal -es, pues respeta la regla de la palabra inglesa y no la del español. En inglés, entonces, es trolls y no troles como sería en castellano, como por ejemplo: Don't feed the trolls o No alimentes a los troles.

Siguiendo la misma línea, la Guía para los nuevos medios y las redes sociales Escribir en internet de la Fundación del español urgente (Fundéu) (2012: 491), señala que trol es una voz coloquial que alude al alborotador o polemista participante en foros cibernéticos, «(...) En los albores de los foros electrónicos en los grupos de noticias (Usenet ${ }^{15}$ ) y otros grupos en la web, algunos veteranos se mofaban de los novatos -que hacían preguntas ya resueltas anteriormente- enviando un mensaje a la lista, en apariencia cándido, en el que preguntaban algo obvio para que los más osados respondieran y criticaran su supuesta ignorancia. En poco tiempo, el término empezó a hacer referencia a la persona osada que critica o reprende con ligereza (es decir, el que respondía al trolling) y, al poco, pasó a denominar, en general, a una

14 El término inglés aquí se refiere a la criatura representada como un gigante o un enano. El plural agrega solo una -s, pues la mayoría de las palabras inglesas forman el plural de este forma.

15 Acrónimo de Users Network (Red de usuarios), que consiste en un sistema global de discusión en Internet, que evoluciona de las redes UUCP. 
https://doi.org/10.46744/bapl.201802.012

persona que molesta, insulta o demuestra una manifiesta negatividad dentro de un foro en internet».

La guía de Fundéu relaciona también sus inicios con el verbo inglés to troll, pero añade la acepción 'pescar con curricán'16 o, lo que nosotros llamamos, cucharilla, técnica de arrastrar lentamente un señuelo o un anzuelo con cebo desde una embarcación en movimiento; por extensión 'servir como señuelo para atraer la atención de alguien', o sea, el novato que caía en la trampa y respondía. A esto se le llamaba 'pescando novatos' o 'trolear novatos', en inglés, trolling for newbies. Así, aunque el término solo se refería a la práctica o acción de trolear, por asociación metonímica pasó a designar al practicante en sí, esto es, el que realiza el troleo, o sea, el trol o troleador.

Trolling es el gerundio o participio presente del verbo to troll, es una palabra extranjera «manifestación que se ha popularizado en foros de internet, páginas de Facebook y en los comentarios en las versiones digitales de revistas y periódicos, que son bombardeados con insultos, provocaciones y amenazas» ${ }^{17}$. La traducción en español es 'troleando' o 'trolear': Se dice que está troleando el que responde a una persona exclusivamente cosas que sabe con certeza que van a molestarle, o también el que se introduce en un foro con el único objetivo de buscar cizaña entre los que se encuentran debatiendo ${ }^{18}$. Pero se suele usar también el extranjerismo con grafía original trolling cuando significa 'agresión cibernética' o forma parte del ciberbullying o 'acoso virtual'. Claro está que se emplea en español como sustantivo, por ejemplo: El trolling es un fenómeno que puede afectar a todas las personas; Cuantas más vistas y comentarios tenga un video, también es probable que tenga más trolling; Lo que hace que el trolling sea tan común es que cualquiera puede bacerlo ${ }^{19}$. Como sustantivo aparece trolling con la traducción 'troleo'

16 Del portugués corricão, aparejo de pesca de un solo anzuelo, que suele largarse por la popa del buque cuando navega.

17 BBC Mundo. (15 de setiembre del 2011). Trolling: qué es, quiénes lo hacen y por qué. Recuperado de http://www.bbc.com/mundo/noticias/2011/09/110915_trolling_que_es_ tsb.shtml?print $=1$

18 Ejemplo recuperado de http://www.quesignifica.org/trolear/

19 ¿Qué es exactamente el trolling? Recuperado de https://www.enplenitud.com/que-esexactamente-el-trolling.html 
https://doi.org/10.46744/bapl.201802.012

en castellano: Los comentarios que busquen el troleo serán eliminados y los usuarios bloqueados ${ }^{20}$; El troleo de la esposa de Pedro Sánchez a Ínigo Errejón. El xenismo también expresa 'búsqueda cuidadosa y sistemática de un área por algo', pero solo se da este uso en inglés: I spent tonight trolling the Internet for expensive lighting gear, ya que en español traducimos la palabra trolling como buscar: 'Pasé esta noche buscando en Internet equipos de iluminación costosos'.

Trolerola son coloquialismos que terminan con el sufijo -ero, adjetivos y sustantivos derivados a partir de radicales nominales, como en este caso trol. Como sustantivos, el mismo sufijo indica el oficio u ocupación del trol, es decir, 'el que dice trolas'. Trola, es un sustantivo que en España significa 'mentira, falsedad o engaño': Que no me contéis trolas. El trolero o trolera es el embustero o embustera, el mentiroso o mentirosa: WhatsApp, nueva vía de engaño para los troleros ${ }^{21}$; Aguirre: "La mentirosa, la trolera Maestre, distingue entre escraches buenos y malos» ${ }^{22}$. Como adjetivo, el sufijo -ero indica el carácter o la condición moral, aquí sería el engañador o engañadora: La reportera trolera ${ }^{23}$; «Perro trolero» finge haber sido atropellado ${ }^{24}$.

Los neologismos troleado / troleada nacen por la adición de -ado o -ada, sufijos derivativos que, aparte de conformar la primera conjugación verbal (he troleado, ha troleado, has troleado), o sea, ser participios y trabajar

20 El Comercio. (17 de diciembre de 2015). «Trolear» o «trollear»: ¿cómo se escribe esta popular palabra? Recuperado https://elcomercio.pe/redes-sociales/facebook/troleartrollear-escribe-popular-palabra-253497

21 Barrena, I. (26 enero de 2014). WhatsApp, nueva vía de engaño para los troleros en Faro de Vigo. Recuperado de http://www.farodevigo.es/vida-y-estilo/tecnologia/2014/01/26/ whatsapp-nueva-via-engano-troleros/955235.html

22 Antena3. (19 de setiembre de 2017). Aguirre: «La mentirosa, la trolera Maestre, distingue entre escraches buenos y malos». Recuperado http://www.antena3.com/noticias/espana/ aguirre-mentirosa-trolera-maestre-distingue-escraches-buenos-malos_20160425572cbfc 86584a85881907ff8.html

23 Teleprograma.TV (abril de 2011). La reportera trolera. Recuperado de http://teleprograma. diezminutos.es/programas-tv/2011/abril/liliana-lopez-la-reportera-mentirosa-de-elintermedio

24 Puranoticia. (06 de febrero de 2017). «Perro trolero» finge haber sido atropellado. Recuperado de http://www.puranoticia.cl/noticias/tendencias/video-perro-trolero-fingehaber-sido-atropellado-miralo-aqui/2017-02-06/134443.html 
como formas verbales: Laura Bozzo felicitó a la selección en Twitter pero es troleada por hinchas ${ }^{25}$; YouTube: Chávez Jr. es troleado por su propia hija tras derrota con 'Canelo ${ }^{26}$, son capaces de establecer derivaciones de adjetivos y sustantivos respetando sus lexemas o raíces (de trol, troleado/ada): Mira la épica troleada del Estado a los que quieren quitar la palabra "género» del currículo escolar ${ }^{27}$; Maestra 'troleada' ya no dará clases $^{28}$

Por lo expuesto, deducimos que, en el caso de los términos troleado/ troleada, el sufijo denota acción propia de un trol, como bien lo certifica la siguiente construcción: Shirley Arica se burla de Katty García pero reportera le bace troleada épica ${ }^{29}$.

Cabe señalar que existen otras voces con el lexema trol, pero con significaciones distintas a las del mundo internáutico que varían según la región. Así, trola en Argentina y Uruguay significa prostituta, mujer bisexual o lesbiana: Esa mina llegó a la TV, pero no por su buen laburo, sino por lo trola que es; Era una trola, la amiga con quien vivía era su amante. En México, es fósforo o cerillo: Se me acabaron las trolas intentando prender esta vela. En Costa Rica los troles son los pies: Qué troles más grandes.

Tanto en el Diccionario de americanismos (2010) como en el DiPerú (2016) aparece el término trola de uso popular como palabra tabú que alude al pene; el Diccionario de americanismos anota que en Chile es la parte

25 Publimetro. (6 de setiembre del 2017). Laura Bozzo felicitó a la selección en Twitter pero es troleada por hinchas. Recuperado de https://publimetro.pe/redes-sociales/noticia-laurabozzo-felicito-seleccion-twitter-troleada-hinchas-64588

26 La República. (9 de mayo de 2017). YouTube: Chávez Jr. es troleado por su propia hija tras derrota con 'Canelo'. Recuperado de http://larepublica.pe/tendencias/873726-youtubechavez-jr-es-troleado-por-su-propia-hija-tras-derrota-con-canelo

27 Livise, A. (22 febrero de 2017). Mira la épica troleada del Estado a los que quieren quitar la palabra «género» del currículo escolar en Utero.pe. Recuperado de http://utero. pe/2017/02/22/mira-la-epica-troleada-del-estado-a-los-que-quieren-quitar-la-palabragenero-del-curriculo-escolar/

28 El Mañana Estado. (9 de setiembre de 2013). Maestra 'troleada' ya no dará clases. Recuperado de http://elmanana.com.mx/noticia/4960/Maestra-troleada-ya-no-daraclases-.html?fb_comment_id=666079546737985_7334601\#f361bb8d122113

29 Ojo. (16 de junio de 2017). Shirley Arica se burla de Katty García pero reportera le hace troleada épica. Recuperado de https://ojo.pe/ojo-show/shirley-arica-se-burla-de-kattygarcia-pero-reportera-le-hace-troleada-epica-243209/ 
https://doi.org/10.46744/bapl.201802.012

alargada o apéndice de una sustancia o cosa; y en Bolivia, la canica y, en su uso plural, refiere a los testículos.

En dicho diccionario, como en el de coloquialismos y términos dialectales del español de Fitch (2011), encontramos asimismo que el sustantivo masculino trolo en Ecuador, Bolivia, Paraguay, Argentina y Uruguay significa 'hombre homosexual'. En estos dos últimos países también recibe las denominaciones de trolazo, trolín, trolebús: A quella disco es exclusiva para trolos. Pero si enunciamos Me subí en un trolebuis, se refiere al vehículo de tracción eléctrica, ya no al afeminado. Curiosamente en México, específicamente en Tijuana, tiene una acepción distinta: 'persona de clase social alta o que aparenta serlo'. Trolear en Honduras se usa como verbo transitivo con dos significaciones, una en el ámbito del ejército 'castigar a alguien con ejercicios físicos extenuantes': Lo trolearon con 200 sentadillas o culucas; la otra, en los deportes 'derrotar con contundencia al oponente': Lo troleó con un poderoso nocaut. Como verbo intransitivo se emplea en Costa Rica con la acepción de 'realizar un paseo o recorrido largo a pie': Salieron a trolear y demoraron casi tres horas en regresar a casa.

En fin, podemos evidenciar que los curiosos neologismos coloquiales relacionados con el mundo informático y cibernético no se encuentran registrados en los diccionarios académicos de la lengua española. Sí hay definiciones de troll o to troll en los diccionarios ingleses como el Cambridge, el Oxford y otros que aparecen en línea. Como ya hemos mencionado, aparecen en artículos de internet, noticias, foros internáuticos o cibernéticos, también en conversaciones, diccionarios de coloquialismos y jergas on line, mensajes de las redes sociales porque son los canales que más rápidamente se actualizan y llegan en segundos a millones de usuarios. Ana Mancera y Ana Pano en su libro El español coloquial en las redes sociales (2013: 26), justamente, señalan que la facilidad de publicar comentarios, actualizar nuestros estados, subir videos, fotos, así como la inmediatez de las respuestas y las reacciones a lo que hacemos o decimos en un ambiente distendido y la relación vivencial de proximidad entre interlocutores sumada a la preponderancia de la función expresiva promueven el uso de un registro coloquial. 
Usamos en las redes estos coloquialismos y creamos nuevas palabras sin siquiera darnos cuenta. Ya hemos citado a trolles, trolear, trolling, troleadorla, troleando, trolerola, troleadola, etcétera, pero también existen y pueden existir otros neologismos coloquiales creados con base en el lexema trol-, como trolerito/ita, trolerazolaza, trolerín/ina, trolerón/ona, trolerucho/ucha, extrolerola, etc. Del verbo trolear son posibles palabras con desinencias flexivas propias de la primera conjugación verbal como troleé, troleó, troleaba, troleará, trolearía, etcétera.

Por lo tanto, no nos llame la atención que muchos de estos neologismos que se originan del extranjerismo troll, por el continuo uso traspasen a un registro más formal y a otros formatos y se consoliden como parte del léxico común de nuestra habla castellana. Hoy por hoy, dichos neologismos coloquiales los tenemos en el campo informático, internáutico de público preferentemente juvenil, colegial y entre presentadores o conductores de radio y televisión. No obstante, no son excluyentes, pues se escuchan en foros cibernéticos entre personas maduras y adultas, claro está, en menor porcentaje. Debemos saber que algunos investigadores los consideran jergas informáticas, pero esto no quiere decir que sean vulgarismos, expresiones vulgares o replana, pues lo vulgar, por lo general, es cambiante y no se mantiene en el sistema con el paso del tiempo. El neologismo sí y tanto que deja de ser, con el transcurso de los años, un neologismo para convertirse en una palabra cotidiana más de la lengua castellana. Estos neologismos coloquiales ya llevan varios años entre nosotros y, como va la tecnología, es muy probable que se mantengan y se perennicen formando parte del léxico de todos los hispanohablantes. 
https://doi.org/10.46744/bapl.201802.012

\section{BIBLIOGRAFÍA}

Banco de neologismos del Centro Virtual Cervantes. En http://cvc. cervantes.es/lengua/banco_neologismos/busqueda.asp

BRIZ GÓMEZ, A. (2010). El español coloquial: situación y uso. Madrid: Arco Libros.

BRIZ GÓMEZ, A. (1998). El español coloquial en la conversación: esbozo de pragmagramática. Barcelona: Ariel.

CALVO, J. (2016). DiPerú. Diccionario de peruanismos. Perú: F. M. Servicios Gráficos.

CAMBRIDGE ADVANCED LEARNER'S DICTIONARY. (2011). United Kingdom: Cambridge University Press.

DICCIONARIO CLAVE. (2012). Diccionario de uso del español actual. Madrid: Ediciones SM.

English Oxford Living dictionaries. Oxford. Recuperado de https:// en.oxforddictionaries.com/definition/troll

EZQUERRA, M. (2008). La formación de palabras en español. Madrid: Arco libros.

FITCH, R. (2011). Diccionario de coloquialismos y término dialectales del español. Madrid: Arco Libros.

GUERRERO RAMOS, G. (2010). Neologismos en el español actual, Madrid: Arco Libros.

LANG, M. F. (1997). Formación de palabras en español: morfología derivativa productiva en el léxico moderno / Mervyn F. Lang ; adaptación y traducción: Alberto Miranda Poza. Madrid: Cátedra. 
https://doi.org/10.46744/bapl.201802.012

MANCERA RUEDA, A.; PANO ALAMÁN, A. (2013). El español coloquial en las redes sociales. Madrid: Arco Libros.

MIRANDA POZA, J. (1994). La formación de palabras en español. Salamanca: Colegio de España.

MOLINER, M. (2013). Diccionario de uso del español. Madrid: Gredos.

PHARIES, D. (2002). Diccionario etimológico de los sufijos españoles y de otros elementos finales. Madrid: Gredos.

REAL ACADEMIA ESPAÑOLA. (2014). Diccionario de la lengua española, vigésima tercera edición. Madrid: Espasa Libros.

. (2011). Diccionario práctico del estudiante. Barcelona: Santillana Ediciones Generales.

. (2010). Diccionario de americanismos. Perú: Santillana.

SECO, M.; ANDRÉS, O. y RAMOS, G. (2011). Diccionario del español actual. 2. ${ }^{\text {a }}$ ed., revisada y actualizada, 2 vols., Madrid: Aguilar-Santillana.

TASCÓN, M. (2012). Guía para los nuevos medios y las redes sociales Escribir en internet de la Fundación del español urgente (Fundèu). Barcelona: Galaxia Gutenberg.

TUEROS, C. ¿Qué es trolear? En blog Castellano Actual y Perú21, 13 de julio de 2016. 